PACS 42.70.Ln, 42.79.Vb

\title{
Is there any future of optical discs?
}

\author{
A.A. Kryuchyn ${ }^{1}$, V.V. Petrov ${ }^{1}$, S.O. Kostyukevych ${ }^{2}$, K.V. Kostyukevych ${ }^{2}$, \\ A.A. Kudryavtsev ${ }^{2}$, N.L. Moskalenko ${ }^{2}$ \\ ${ }^{1}$ Institute for Information Recording, NAS of Ukraine \\ 2, Shpak Str., 03113, Kiev, Ukraine \\ E-mail: petrov@ipri.kiev.ua \\ ${ }^{2}$ V.Ye. Lashkarev Institute of Semiconductor Physics, NAS of Ukraine \\ 41, Prospect Nauki, 03028, Kiev, Ukraine \\ E-mail: sergeyk@isp.kiev.ua
}

\begin{abstract}
Considered in this paper are causes for cutting compact discs out of information technology market. It has been shown a search of new technological solutions for efficient use of CDs in archive data storage.
\end{abstract}

Keywords: multilayer disc, multilevel recording carrier.

Manuscript received 12.08.13; revised version received 18.09.13; accepted for publication 23.10.13; published online 10.12.13.

\section{Introduction}

Accumulation of knowledge is one of the main tasks for every civilization. At all stages of world development, great attention was paid to creation of means for reliable information storage. In recent years, in relation with huge growth of newly created information volumes, processing giant peta-byte data arrays, high rates in creation of anew carriers as well as accomplishing performances of the earlier designed ones, technologies for processing data are permanently improved. In the course of 30-year history of data storage technologies, there changed were three generations of compact discs, namely: CD (1982), DVD (1996), BD (2004). For this time, the storage size was 30fold increased, and the rate of data exchange - by 100 times. CDs have become and remain up to date as means for mass dissemination and storage of information in the digital form. Their circulations reached 20 billions per year (in $2001-2003$ years).
Summarized in Table 1 are the data about size for optical discs of various types.

Table 1.Growth in the size of optical discs

\begin{tabular}{|c|c|c|}
\hline Carrier type & $\begin{array}{c}\text { Size, } \\
\text { GBytes }\end{array}$ & $\begin{array}{c}\text { Year of } \\
\text { elaboration }\end{array}$ \\
\hline CD & 0.78 & 1982 \\
DVD(DVDS, & $4.7-18$ & 1996 \\
DVD18) & & \\
BD & 25 & 2004 \\
Dual layer BD & 50 & 2004 \\
Duce Fuji & 1000 & 2015 \\
Film & & \\
\hline
\end{tabular}

But in recent years, one can watch a tendency of shortening in use of optical discs. In 2012, the market of this production was lowered by $10 \%$, although the demand for DVD currently grows in developing countries, and for discs of the Blu-ray format - in the 
developed ones. Several manufacturers from Japan and Taiwan [1] have left the world market of optical discs. Information that the company Sony abates its production of optical disc drives [2] reflects a drop of demand for these goods.

This situation is related with many reasons:

- change in approaches to data storage based on cloud technology for data processing; the matter is not in changing one physical carrier by another but in transfer to a new conception of data storage, which is based on web resources;

- availability of high-speed telecommunication channels caused drop in the necessity to create proper archives of multimedia information, computer soft is not bought on discs but is loaded from the web. For example, annual expenses of buyers for acquiring music in the digital format from the web were increased by $17.8 \%$ in 2012 as compared with 2011 (total volume of sales was 5.5 billion pounds), while on physical carriers these were decreased by $12.1 \%$. Although the fraction of music sales on physical carriers was $61 \%$ in 2012 ;

- $\quad$ storage size of optical carriers does not allow to provide recording the currently increasing data volumes in scientific investigations using a unique equipment as well as data of meteorological investigations. The data size obtained in the Large Hadron Collider for one year after filtration reaches 25 PB. To save such a data size, one should use one million discs in the Blu-ray format;

- writable CDs are now cut out by flash memory due to exploitation convenience (simplicity in sampling changes of the content and absence of the special procedure for session finalization);

- notebook manufacturers abandon optical drives that increase the weight of notebooks and prefer convenient small-size flash memory;

- widely used is the practice to pre-load an operation system on a hidden part of winchester, which allows re-loading without optical discs. With emergence of Windows7, the program USB/DVD Tool was developed. It simplifies creation of the load USB flash memory for loading an operation system. When supplying notebooks without an optical drive, MacbookAir provides a consumer with the operation system MacOSX 10.6 on a flash memory.

Many of computer system designers and manufacturers do not believe in future of optical discs, but developers of these discs work at their perfection, search for new ranges and possibilities to efficiently apply them. Despite shortening production of optical discs and decrease in the number of ranges for their application, compact discs are still rather widely used for storage of various types of information, therefore it is necessary to determine ranges for their effective use and perspectives in improving their performances.

\subsection{Analysis of methods for improving optical disc performances.}

One of the main directions for improving performances of optical discs is creation of bulk carriers, both multilayer and holographic ones, as well as carriers with multilevel recording.

Solving the task to create bulk carriers was multiply tried, but only bilayer discs found their wide application. First of all, it is related with absence of technical solutions that would allow to develop technology for mass production of multilayer discs. And, as a consequence, the outstanding samples of multilayer optical discs (for instance, Hitachi 2006, the storage size $340 \mathrm{~GB}$ ) had a high cost of data storage [3].

Several companies announced their readiness to begin production of optical multilayer discs with the size 1 to $2 \mathrm{~TB}$, including the company FolioPhotonics that offered 64-layer optical discs [4].

From the technical viewpoint, the most technically grounded are statements of FijiFilm representatives concerning creation of a terabyte multilayer disc where the size of separate layers reach 20 to $25 \mathrm{~GB}$. They plan to begin production of these discs in 2015 [5]. Recording and rendering the data in these multilayer discs are based on using the effect of two-photon light absorption.

As early as the first works performed by Academician A.L. Mikaelyan et al. in 70-es of the last century, it was pointed at the potential possibilities of holographic methods for information registration at terabyte sizes of carriers with data transfer speeds exceeding those of recording or reading out in up-to-date memory on hard magnetic discs. But this technology did not obtain wide application for the following reasons:

- absence of registering materials with a necessary complex of properties to provide high-speed recording, reliable data read-out and long-term data storage;

- $\quad$ high cost of the optical system in the facility for holographic memory;

- $\quad$ high read-out speeds can be reached only under parallel signal processing.

However, the developments in this direction are not stopped, and time-to-time there arise reports on elaboration of experimental samples of holographic memory with high performances, but all of them are applied in narrow specialized areas.

Both in the flash memory and optical discs, the principle of multi-level (ML) recording is offered. This principle was developed by the American company Calmetrics (it is a member of ML Alliance headed by TDK corporation) [6]. The main difference of ML recording from traditional technology is that a print on the carrier possesses several states (up to 8). When using the carrier based on dyes, in dependence on the light power level, prints with different reflection coefficients are formed. An important advantage of ML discs is simplicity of modernization of standard drives for 
reading-out from $\mathrm{CD}$ (only controller is changed). They plan production of ML discs in the DVD format [6].

\subsection{Perspectives in application of optical discs for long-term information storage.}

Manufacturers of optical memory and discs try to reduce dimensions of optical memory: in particular, they managed with lowering the thickness of their facilities from $12.7 \mathrm{~mm}$ down to $9.5 \mathrm{~mm}$ [7]. Also, the possibility to lower the diameter of optical discs down to $60 \mathrm{~mm}$ is considered [6]. A number of successful developments used in optical memory systems will unconditionally find their application in other memory systems with a high density of recording. For example, near-field systems to focus laser radiation that provide focusing this radiation into a spot of the 10-nm diameter, which because of low optical transmission cannot be directly used for data recording, however, could be applied in combination with other recording systems. Near-field focusing systems find their application in the systems of magnetic memory with laser heating the area of recording (HAMR). These facilities for magnetic memory will have the size up to $20-30 \mathrm{~Tb}$.

Being based on achieved performances and rather long exploitation experience, the main area of optical disc use can be considered as long-term information storage [8]. Just this direction is meant when developing new types of optical discs. However, it should be noted that one of the reasons for refusing the use of CD in upto-date computers is there short life span and increase of failures amount with time [9]. To realize potentially high possibilities of optical carriers in providing long-term data storage, they need several developments. With account of a large acquired experience in using optical discs, analysts note that $\mathrm{CD}$ are very fragile, subjected to scratches and strains of various kinds, which can result in their destruction at high read-out speeds [10]. Specially developed optical discs for long-term storage got their title as "professional discs".

Currently investigations are performed in directions both for increasing the stability of characteristics of substrates and photosensitive layers used for information recording. Using optical disc substrates made of highly stable materials allows obtaining the optical carriers with a long warranted operation life. It is assumed to use in CD both substrates from silicate (borosilicate) glasses and substrates from monocrystalline materials. Sapphire substrates can provide increasing the terms of warranted data storage, however, it requires usage of special readout systems $[11,12]$.

Increase in duration of data storage on writable optical discs is promoted by using the non-organic thermosensitive materials with ablation recording [13] and the photosensitive ones in systems with irreversible phase recording [11. 14] that are widely used in UDO carriers produced by the Plasmon company [14].

Development and production of professional optical assigned for long-term data storage are provided by a number of companies that use various technologies to increase terms of data storage (Table 2).

Table 2.Characteristics of professional optical dises for long-term data storage

\begin{tabular}{|c|c|c|c|}
\hline Carrier type & $\begin{array}{l}\text { Size, } \\
\text { GBytes }\end{array}$ & Developer & $\begin{array}{c}\text { Term of } \\
\text { storage, } \\
\text { years }\end{array}$ \\
\hline UDO & 120 & Plasmon & $>50$ \\
\hline M-disc & $\begin{array}{l}\text { 9.4(form } \\
\text { ат DVD) }\end{array}$ & Millenniata & 1000 \\
\hline $\begin{array}{c}\text { Glass- } \\
\text { Master Disc }\end{array}$ & 4.1 & Syylex & 1000 \\
\hline
\end{tabular}

Optical discs with characteristics summarized in Table 2 have already passed their certification tests, which confirms the opportunity to use these carriers for long-term data storage. The developed carriers on silica and sapphire substrates are now in the testing stage. A general approach in creation of optical discs for longterm information storage consist of that it is offered to use a micro-relief way of data representation on carriers as well as to use high-stable materials for substrates of information carriers. To provide long-term data storage, it seems possible to use optical carriers of the ROM type where the micro-relief structure is created inside a substrate made of special materials.

\section{Conclusions}

1. With account of modern tendencies in development of technology for data storage, optical discs will gradually lose their position as a mean of mass dissemination of computer information.

2. The main area of using the optical discs will be archive data storage. In this case, preference will be given to optical carriers specially developed for these targets.

3. Application of optical discs for large information arrays will depend on how successfully introduced will be bulk optical carriers as well as the latter developed for multi-level recording.

Achievements obtained in the area of near-field optical recording will be used in the systems for magnetic recording (HAMR technology).

\section{References}

1. Optical discs will get up by $50 \%$. [Digital resource]. Access mode: http://www.dailycomm.ru/m/21101/. Title from the screen.

2. Mikhailov P. Sony abates production of optical disc drives [Digital resource] Access mode: http://www.winline.ru/news/sony_prekrashchaet_v ypusk_privodov_opticheskikh_diskov.php. Title from the screen.

3. Optical discs of an unbelievable size [Digital 
resource]. Access mode: http://topsoc.ru/hitech/opticheskie_diski_neveroyat nogo_razmera-63/. Title from the screen.

4. Vasilkov A. FolioPhotonics makes production of the first laser discs of 1 and 2 TB sizes [Digital resource]- Access mode: http://blogs.computerra.ru/41860. Title from the screen.

5. Terabyte optical discs from FujiFilm by 2015 [Digital resource]. Access mode: http://news.samaratoday.ru/news/219054/. Title from the screen.

6. Asmakov S. Optical discs with multilevel recording // ComputerPress. 2002. No 2. - P. 9.

7. Fog future does not allow to develop for manufacturers of optical drives [Digital resource]. Access mode: http://nvworld.ru/news/hazy-futurestops-odds-evolution/. Title from the screen.

8. Perspectives for development of information carriers [Digital resource]. Access mode: http://www.obercom.ru/article2.html. Title from the screen.

9. Optical discs M-DISC can store data for 1000 years [Digital resource]. Access mode: http://www.macdigger.ru/macall/opticheskie-diskim-disc-mogut-xranit-dannye-1000-let.html. Title from the screen.
10. Past for DVD, and future for USB? [Digital resource]. Access mode: http://myubuntu.ru/hitech/proshloe-za-dvd-abudushchee-za-usb. Title from the screen.

11. Petrov V.V., Kryuchin A.A., Rubish V.M. Materials for promising optoelectronic facilities. Kyiv, "Naukova Dumka", 2012. 335 pages.

12. Patent 73611 Ukraine, IPC7 G 11 B 7/24. Carrier for long-term information storage. Petrov V.V., Seminozhenko V.P., Puzikov V.M., Danko O.Ya., Kryuchin A.A., Shanoilo S.M., Butenko L.V., Kossko I.O. Published 15.08.2005, Bulletin No 8.

13. Developed are the first "ageless" optical discs [Digital resource]. Access mode: http://future24.ru/razrabotany-pervye-vechnyeopticheskie-diski. Title from the screen.

14. Petrov V.V., Kryuchin A.A., Shanoilo S.M., Kravets V.G., Kossko I.O., Belyak Ye.V., Lapchuk A.S., Kostyukevych S.O. Super-dense optical registration of information. Executive Editor O.G. Dodonov. National Academy of Sciences of Ukraine, Institute for Information Recording. Kyiv, NAS of Ukraine, 2009. 282 pages. ISBN 978-96602-5027-7. 